I Pontifícia Universidade Católica do Rio de Janeiro (PUC-Rio),

Departamento de Ciências Sociais, Rio de Janeiro, RJ, Brasil

felipesussekind@puc-rio.br

https://orcid.org/0000-0002-9899-1230

Felipe Süssekind'

\title{
A HISTÓRIA DE GIGANTE: CONSERVAÇÃO E CAÇA NO PANTANAL'
}

Em I977, o já então renomado naturalista e zoólogo norte-americano George Schaller chegou à Fazenda Acurizal, na região centro-oeste do Pantanal, ${ }^{2}$ para dar início ao que seria o primeiro estudo de campo científico sobre a onça-pintada em seu ambiente natural. O estudo foi viabilizado por parceria entre a New York Zoological Society (atual Wildlife Conservation Society) e o Instituto Brasileiro de Desenvolvimento Florestal (IBDF), órgão ambiental do governo brasileiro na época (Crawshaw, 2006b). Seria um dos primeiros trabalhos científicos a utilizar no país a radiotelemetria, método característico da moderna biologia da conservação, baseado na captura de animais e no uso de transmissores de rádio acoplados a coleiras. ${ }^{3} \mathrm{~A}$ onça, ou jaguar (Panthera onca), era até então o menos conhecido dos grandes felinos, e Schaller (I972) trazia na bagagem trabalhos importantes com grandes mamíferos, entre eles um estudo de referência sobre os leões do Serengueti. ${ }^{4}$

A pesquisa resultou em artigos científicos pioneiros sobre a ecologia da onça pantaneira e de suas presas, em particular a capivara (Schaller \& Crawshaw, I980; Schaller \& Vasconcelos, I978). Além da produção estritamente científica, entretanto, Schaller sempre trabalhou também com relatos de suas experiências de campo, textos para um público não especializado, de divulgação científica. Nesse âmbito, escreveu dois relatos curtos a partir de sua estada no Brasil - um sobre a onça e outro sobre a capivara - nos quais descreve a experiência de campo e comenta alguns dos resultados e as dificuldades enfrentadas durante o projeto no Pantanal (Schaller, 2007). 
O texto sobre o jaguar, publicado originalmente em I980, é o que nos interessa aqui. Trata-se de um relato pessoal que descreve as tentativas iniciais do pesquisador de capturar onças para a colocação de coleiras de rádio. A narrativa é pontuada por dois grandes problemas. O primeiro deles se refere ao processo de captura dos felinos; o segundo à resistência da comunidade local diante da ideia de conservação de um animal visto como ameaça ou fonte de prejuízos.

Para o primeiro problema, Schaller encontra uma solução; para o segundo, como veremos adiante, não. Em relação às tentativas de captura, ele afirma:

Os jaguares não só me enganavam, como pareciam realmente zombar dos meus esforços: uma fêmea passou vagarosamente pelas nossas redes enquanto dormíamos, e um macho depositou sua presa - uma capivara não comida - a Ioo metros do acampamento. [...] Uma vez que minhas tentativas para capturar um jaguar tinham falhado, recorri aos métodos brasileiros tradicionais de caça (Schaller, 2007: 69)..$^{5}$

Ao longo da primeira metade do século XX, eram bastante comuns no Pantanal os "safáris", nos quais visitantes em busca do jaguar contratavam caçadores profissionais para expedições guiadas. Essa prática regional está documentada em uma série de relatos escritos por caçadores naturalistas, e a seu respeito falarei adiante. Nessa situação peculiar, se desenvolveu um sistema especializado de caça em torno do uso de cães farejadores e das habilidades de caçadores nativos conhecidos como zagaieiros.

Os conhecimentos desses caçadores, humanos e caninos, acabaram sendo fundamentais na captura de onças para o estudo científico, o que se evidencia no trecho em que Schaller (2007: 69-70) faz referência àqueles que o auxiliaram em seu projeto:

Richard Mason, um expatriado britânico, possuía a melhor matilha de cães caçadores do oeste do Brasil, onde acompanhava clientes estrangeiros em caçadas, até que uma lei federal de ig67 protegendo o jaguar afetou seu negócio. Ele concordou em ajudar e chegou em Acurizal com cinco cachorros e seu mateiro, Manuel Dantas, que como caçador e guia tinha passado 25 anos no Pantanal.

A caça é regulamentada no Brasil desde 1967, quando foi declarada proibida para qualquer espécie da fauna silvestre nativa. ${ }^{6} \mathrm{~A}$ lei vigente foi modificada pela última vez em I998, estabelecendo punições mais severas para os infratores. ${ }^{7} \mathrm{Na}$ prática, porém, muitos proprietários rurais pantaneiros continuam até hoje a reivindicar o direito de abater animais que atacam o gado, usando como argumento a brecha que existe na legislação no que se refere aos chamados "animais nocivos". ${ }^{8}$ Em uma situação em que a atitude dos proprietários rurais determina o que acontece dentro das fazendas, sendo a fiscalização quase nula, a caça é apontada, no campo da conservação, como a principal ameaça para a espécie no nível regional (Cavalcanti et al., 20ıo; Silveira et al., 2008; Morato et al., 2006). 
Nas práticas locais, tais como se consolidaram historicamente, os cães farejadores são elementos cruciais. Cachorros "onceiros" têm a reputação, no Pantanal, de ser capazes de rastrear os predadores a partir das trilhas de olfato deixadas em carcaças de animais ou "batidas" (rastros ou pegadas). Não por acaso, portanto, um dos principais personagens da captura narrada por Schaller (2007: 70) é um cão:

O cão líder, Gigante, um mestiço amarelo, castrado, ia na frente, examinando a floresta em busca de rastos frescos de jaguar. Os outros cães ganiam e se agitavam em suas guias enquanto seguíamos um latido ocasional de Gigante. Dantas ia na frente, abrindo uma picada com golpes curtos de seu facão. "Hup, brrriii," Richard gritava de vez em quando, incentivando Gigante a prosseguir e deixando que ele soubesse que ainda estávamos com ele.

Os cães especializado nesse tipo de perseguição são designados regionalmente como "mestres". São reconhecidos por só seguir o rastro da onça e o de nenhum outro animal - o que tem implicações no valor dado ao cachorro e também na reputação do caçador. ${ }^{9}$ O sentido do faro é o que possibilita o rastreamento, sendo que a comunicação se dá por meio de mensagens sonoras - o "barruar" do cão, de um lado, e os sons produzidos pelos caçador, de outro.

A narrativa continua seguindo o mestre canino:

Um dia estávamos na região mais remota de Acurizal, um desfiladeiro sombrio, coberto de mata. Gigante estava na frente - seus latidos nos diziam que ele estava interessado em alguma trilha recente, $[\ldots]$ enquanto nós nos demorávamos no leito seco de um riacho, sem saber onde procurar em seguida. De repente, ele latiu várias vezes, como se estivesse sendo atacado. Depois, silêncio (Schaller, 2007: 70).

O que torna possível uma caçada desse tipo é a relação de aliança estabelecida entre humanos e cães. Estes últimos sozinhos não seriam capazes de abater uma onça (ao contrário, muitas vezes são eles é que dela se tornam vítimas), ao passo que, sem os cães, os caçadores humanos seriam incapazes de localizar o felino. ${ }^{\text {Io }}$ Acuadas pelos latidos e pela perseguição, as onças em geral sobem na copa das árvores, onde se tornam alvos fáceis para os caçadores armados.

Schaller (2007: 70) relata então a soltura do restante da matilha e o encontro da onça acuada:

Corremos atrás dos cachorros, esbarrando em galhos de palmeira e caindo em buracos, até chegar onde eles estavam reunidos, em volta de uma árvore inclinada sobre o leito do rio. Excitados, pulavam sobre o tronco e mordiam as lianas nele penduradas.

Até aqui, o texto se assemelha a um típico relato de caça. É somente no encontro com a onça que o contraste com os métodos tradicionais se oferece:

Deitada em um galho cerca de sete metros acima do caos estava uma onça-pintada, uma fêmea jovem, estranhamente calma enquanto olhava inexpressivamente para nós e os cachorros histéricos. "Finalmente nos encontramos", disse para mim mesmo. Enquanto eu enchia uma seringa com uma droga para dormir, Dan- 
tas tirou os cachorros dali e os amarrou numa árvore a algumas dezenas de metros de distância (Schaller, 2007: 70-7I).

Nesse caso, o "caçador" não atira. Em vez disso ele prepara o anestésico. Depois descreve a espera pelo efeito da droga e o encontro da onça adormecida cem metros adiante do local onde foi atingida. Por fim, observa:

Para recompensar Gigante por seu excelente trabalho, nós o levamos até o felino. Embora aquelas garras o tivessem ferido poucos minutos antes, ele olhou para o corpo imóvel sem expressão. Nós não sabíamos na hora que essa seria a última caçada do cão, que sua vida estava se esvaindo lentamente (Schaller, 2007: 7I).

O comentário final é o obituário de Gigante. Ferido gravemente durante a perseguição, ele não resiste e acaba morrendo por conta de uma hemorragia. A morte do cão aponta, nesse caso, para um novo paradigma: ela é apenas uma fatalidade, enquanto a onça não só sobrevive, como recebe uma coleira de rádio e passa a ser seguida por meio de dispositivos associados a toda uma nova gama de atores.

Este outro trecho se refere ao estranhamento do caçador nativo diante da novidade. Em seguida, Schaller (2007: 72) registra os dados tomados na captura:

Em outras caçadas, o felino já estaria morto há muito tempo. "Eu estaria tirando sua pele agora", Dantas comentou enquanto nós nos preparávamos para registrar seus dados vitais. ${ }^{\text {II }}$ Ela pesou 70 quilos e mediu quase dois metros da ponta do nariz à ponta do rabo - um animal pequeno pelos padrões do Pantanal, onde jaguares são maiores do que em qualquer outro lugar na América do Sul. Richard, que pesa cuidadosamente troféus, me disse que uma fêmea adulta pesa em média 90 quilos e que seu macho mais pesado chegou a I20 quilos. (...) Peter e eu colocamos o colar de rádio.

Desde I978, mediante um convênio entre o IBDF e a Fundação Brasileira para a Conservação da Natureza (FBCN), o projeto no Pantanal contou com a participação de Peter Crawshaw, biólogo brasileiro que se tornaria referência na consolidação da pesquisa e conservação de carnívoros no país. Escrevendo, em uma perspectiva histórica, sobre a conservação da onça-pintada, Crawshaw chama atenção para o fato de que o conhecimento produzido sobre a história natural da espécie antes da vinda de Schaller ao Brasil, em I977, era embasado principalmente na experiência de caçadores, viajantes ou naturalistas.

A principal referência mencionada por ele é o livro Jaguar hunting in Mato Grosso, de Antonio de Almeida, publicado em I976 - apenas um ano antes da chegada do pesquisador norte-americano (Crawshaw, 2006b: I8). Lançado pela editora britânica Safari Press, Jaguar hunting é um misto peculiar de história natural e narrativa de aventuras, com caçadas nas quais o autor acompanha visitantes de diversas partes do mundo. O livro traz uma série de observações acerca do comportamento e dos hábitos alimentares das onças, incluindo dados sobre conteúdos estomacais, medidas dos crânios e peso de 
cada um dos animais caçados. Produz, com isso, dados quantitativos que serviram de referência para estudos científicos posteriores.

Além de ser uma referência bibliográfica, contudo, Antonio de Almeida é também mais um participante da captura da onça-pintada narrada acima por Schaller. Ele vinha a ser associado do "expatriado britânico" Richard Mason (Schaller, 2007) no agenciamento de caçadas guiadas para turistas interessados em ter o jaguar como troféu. ${ }^{22}$

Em meio às caçadas narradas em Jaguar hunting, reencontramos nosso cão mestre:

Foi aqui que encontramos Gigante, um cão mestiço castrado que pertencia a um vaqueiro local e que nos acompanhou como guia durante essa caçada. Gigante nos seguiu de perto durante os primeiro três dias, perto demais, de fato, sem demonstrar nenhum interesse em caçar (Almeida, I976: I17).

Do desinteresse inicial do cão, o autor relata a seguir sua incorporação ao grupo de onceiros a partir das experiências vividas naquela caçada:

Um dia soltamos a matilha num rastro de puma, e todos exceto o mestiço estavam latindo a cerca de 200 metros a nossa direita. Então começamos a ouvir um latido fraco à esquerda e olhando melhor vimos um puma em cima de uma árvore, com Gigante parado sozinho embaixo. Depois disso, é claro, nós o olhamos com muito respeito e, à medida que ele ia ficando cada vez melhor durante essa caçada, na qual mais três felinos foram mortos, nós mais ou menos obrigamos o vaqueiro a nos vendê-lo (Almeida, 1976: II7).

A conclusão desse trecho do livro é em tom de homenagem, resumindo bem a importância do cão para o autor. Chama atenção, nesse caso, o uso da locução verbal indicando a continuidade da ação no presente; ou seja, o fato de que ele escreve com Gigante ainda vivo: "Desde então, o latido desse eunuco magro tem sido sempre um sinal seguro do rasto fresco de um felino" (Almeida, I976: II7).

O livro de Almeida se inscreve, como veremos adiante, em uma linhagem de caçadores-naturalistas que remonta à publicação do relato de Theodore Roosevelt sobre sua visita ao Brasil, no qual abundam narrativas de caçadas de onças. O texto de George Schaller sobre sua experiência com o jaguar no Pantanal, por sua vez, estabelece um marco temporal para um novo gênero. Juntamente com os artigos científicos que publicou com seus colaboradores na pesquisa, ele se situa no início de uma produção consistente sobre a onça-pintada no Pantanal que se estabeleceu na área da biologia da conservação ao longo dos últimos 40 anos.

Quando aproximamos os dois autores, um dos elementos que se torna visível é a mudança de paradigma em relação à onça: a fera ameaçadora do passado sendo substituída pela espécie ameaçada do presente. A aproximação, porém, revela-se mais complexa do que isso. Personagem dos textos de Almeida, o caçador, e de Schaller, o biólogo da conservação, Gigante atravessa uma 
fronteira problemática. Em um primeiro momento, afinal, os autores estariam em campos opostos no que se refere a suas práticas. De um lado, aqueles que trabalham pela conservação da espécie; de outro, aqueles que trabalham para sua eliminação. A ideia de uma fronteira estável, contudo, não descreve bem o que se passa no Pantanal, especialmente quando olhamos para as múltiplas interações colocadas em jogo nessas práticas.

Em I9I3, Theodore Roosevelt, então ex-presidente dos Estados Unidos, ${ }^{\text {I3 }}$ participou de uma expedição na companhia de Cândido Rondon que tinha como objetivo desbravar uma região ainda não cartografada do oeste brasileiro. A viagem foi tema do livro Nas selvas do Brasil, publicado em I9I4 nos EUA (Roosevelt, I976). Além das intempéries enfrentadas na navegação pelo rio da Dúvida, ${ }^{\mathrm{I} 4}$ o livro narra uma série de caçadas de onça durante a passagem do autor pelo Pantanal.

Analisando o que batizou com precisão, em um texto de 1984, de Teddy Bear Patriarchy, ${ }^{15}$ Donna Haraway apresenta Roosevelt como o grande patrono do Museu Americano de História Natural em Nova York. A figura do ex-presidente, nesse contexto, está ligada a um ideal no qual a caça esportiva se associa a um projeto naturalista em que os exemplares abatidos são taxidermizados e preservados em coleções zoológicas. ${ }^{16}$ Haraway tem a capacidade admirável de articular questões socioculturais, políticas e ecológicas, em uma leitura em quem humanos e não humanos, cientistas e não cientistas, são igualmente protagonistas de uma história conjunta. Ela mostra, nesse caso, como o estilo literário de Roosevelt remete a uma aliança peculiar entre desbravamento das fronteiras, refinamento pessoal e desenvolvimento científico, reforçando a imagem paternalista do autor como chefe da nação.

O livro do ex-presidente norte-americano é o mais antigo da série de relatos que estou apresentando aqui, os quais se voltam para as "selvas" brasileiras tendo o Pantanal como cenário e a onça como protagonista em histórias de caça. Uma série que se encerra, de certa forma, com a publicação de Jaguar hunting in Mato Grosso, já nos anos I970 - livro no qual, não por acaso, a figura de Roosevelt é evocada de forma reverente em diversas passagens.

Outro exemplo literário conhecido, no que se refere a narrativas de caçadas, é Sasha Siemel, um caçador nascido na Letônia que viveu na região sul do Pantanal na primeira metade do século XX. O primeiro livro autobiográfico de Siemel (Tigrero, de I953), traz como elemento central de sua trama o encontro do autor com o índio Joaquim Guató, o detentor dos segredos da técnica única de caça, ligada ao uso de uma lança denominada zagaia; técnica que Siemel seria o "primeiro homem branco" a experimentar. Há um contraste, formulado no livro, entre as imagens do índio corrompido pela bebida, de um lado e, de outro, o perfeito caçador, dotado de "qualidades e instintos quase sobre-humanos" (Siemel, I953: 27). 
O caçador branco, nesse caso, admira o "tigre" rado, e enfrenta-o extrapolando o código da nobreza esportiva, colocando em risco a própria vida. Ao mesmo tempo, apresenta em segundo plano o sacrifício do animal como algo necessário, um serviço para a comunidade. A descrição do animal nocivo aparece, por exemplo, quando o autor é questionado pela futura esposa, em Nova York, sobre a importância de se preservar os animais selvagens: "Eu expliquei [...] que também não gostava de matar animais; e que minha caçada era para abater um animal assassino, do mesmo modo que um policial seria capaz de matar um assassino humano" (Siemel, I953: 274). Neste outro trecho, argumenta: "O puma era um destruidor de gado e um dos raros animais da selva que matam unicamente por matar. [...] Eles [pumas] são covardes" (Siemel, I953: 276).

Os termos usados para descrever animais - "assassino", "covarde" - contrastam, entretanto, com as características de nobreza, bravura e honra da fera enfrentada pelo zagaieiro. "Você vai ver que o tigre não responde à lógica humana, e não entende o significado de piedade. [...] O tigre é um dos inimigos mais honrados que você irá encontrar" (Siemel, I953: I6). A ambiguidade entre o animal nocivo e o adversário de valor atravessa toda a narrativa de Siemel, e é essa ambiguidade que define a identidade heroica do caçador como alguém capaz de eliminar uma ameaça e ao mesmo tempo sobrepujar um "inimigo honrado". ${ }^{18}$

A onça é o adversário contra o qual o autor prova suas qualidades e preenche seu espírito, bem de acordo com o modelo de história natural preconizado por Roosevelt e analisado por Donna Haraway. Partindo da escultura com a figura patriarcal do ex-presidente na entrada do Museu de História Natural, Haraway se volta para o trabalho de Carl Akeley, o caçador, naturalista, escultor e taxidermista que deu forma às exposições públicas do acervo. ${ }^{19} \mathrm{De}$ acordo com ela, as esculturas em bronze de Akeley representando os caçadores de leão nandi, do leste da África, somadas às filmagens desse tipo de caça, se traduzem em uma imagem que representaria, na narrativa do museu, a essência da caçada. Algo que viria a embasar, em uma perspectiva evolucionista, o modelo do "homem caçador" como protagonista da história humana (Haraway, I 989: 28). ${ }^{20}$

O livro de Sasha Siemel parece nos fornecer uma imagem do mesmo tipo. Nele, o autor descreve sua transformação em um tipo especial de caçador, o zagaieiro, que enfrenta sozinho o "tigre", armado apenas com uma lança. O "homem contra a natureza nos mais primitivos termos" (Siemel, I953: 27). A essência da caçada. O sentimento evocado é de comunhão com a natureza e intimidade com o território, extrapolando em muitos aspectos o elemento pragmático da eliminação de animais.

Assim como Siemel, Antonio de Almeida é caçador profissional e guia de safáris internacionais. Seu Jaguar hunting, publicado duas décadas depois 
do Tigrero!, de Siemel, é influenciado diretamente pelo estilo de seu predecessor, além de voltado para o mesmo público de caçadores esportivos e entusias tas da caça. A ambiguidade não formulada entre admiração e eliminação é própria de um determinado espírito de época, evocado por Almeida em tom nostálgico. As citações de Roosevelt e de Siemel no livro repetem sempre uma mesma fórmula: "Roosevelt himself", "Sasha Siemel himself", o que demonstra a autoridade e a distinção moral conferidas a essas figuras pelo autor.

O capítulo "O papel do caçador" (Almeida, I976) opõe a "caça esportiva" (sport hunting) e a "caça furtiva" (poaching), expressando também uma hierarquia cujos aspectos etnocêntricos permanecem não questionados. A posição assumida por ele frente aos "ecologistas de poltrona", por sua vez, aponta para o que seria uma decadência da sociedade moderna urbana contra a qual o caçador esportivo estabelece seu código moral na qualidade de defensor da vida selvagem.

O livro traz também uma ambiguidade eloquente entre a arma e a câmera. Quando fala sobre os equipamentos utilizados no campo, Almeida (I976: I45) cita sua marcas preferidas de armamentos: "Quanto às armas, o revólver Smith \& Wesson, é claro, já tem uma longa tradição em Mato Grosso, onde nenhum homem cavalga desarmado" e, na sequência do mesmo capítulo, acrescenta suas câmeras prediletas: "Não é de espantar, portanto, que minhas duas Pentaxes tenham tido sua quota de mergulhos" (Almeida, I976: I48). Nesse caso, como observa Donna Haraway a respeito de Akeley, atirar e clicar (em inglês usa-se o mesmo verbo, to shoot) são expressões do mesmo desejo de documentação.

Sobre os escritos de Carl Akeley, Haraway observa ainda que, quando fala a respeito dos caçadores de leão africanos que esculpiu em bronze, Akeley se refere a eles como "homens", sendo que "em todas as outras circunstâncias, ele se refere aos africanos adultos como rapazes (boys)" (Haraway, I989: 28). O papel do nativo no relato do caçador branco é, nesse caso, quase sempre o de um auxiliar tratado de forma paternalista, a não ser nos momentos em ele representa um tipo ideal, uma figura do homem em estado natural.

Em Jaguar hunting, todos os caçadores nativos que trabalham com Almeida, homens adultos e caçadores experientes, são tratados de forma semelhante. Como nesta passagem: “...antecipando a caçada do dia seguinte, ouvindo o zumbido dos insetos, as vozes abafadas, sonolentas dos rapazes [boys] em suas redes" (Almeida, I976: I63-I64), ou então nesta outra: "Se tivemos um rapaz [boy] mais corajoso do que Raimundo, foi Gonçalo” (Almeida, I976: I66, grifos meus).

O paternalismo presente nesses trechos, assim como o protagonismo dos caçadores "brancos", não anula, porém, a admiração do autor em relação a seus colaboradores locais. Almeida não se cansa, nesse sentido, de chamar a atenção para as habilidades dos pantaneiros na caça. Descreve em detalhes o modo 
como lidam com os cães, assim como os instrumentos sonoros fabricados com cabaças para imitar o som das onças. Os caçadores nativos, antigos zagaieiros, apresentam, no entanto, sempre essa ambiguidade fundamental: ora eles aparecem como heróis idealizados, ora como auxiliares subalternos do caçador branco. ${ }^{21}$

No que se refere à relação do autor com os modos de vida locais, Jaguar hunting pode ser aproximado, em sua dimensão propriamente etnográfica, a alguns dos poucos trabalhos antropológicos voltados para a vida nas fazendas do Pantanal. O melhor exemplo, nesse caso, talvez seja a etnografia de Álvaro Banducci (2007), realizada com vaqueiros do Pantanal da Nhecolândia, na qual a economia das relações locais é descrita a partir de uma articulação entre os pares bravo e manso, doméstico e selvagem. Banducci (2007: I 25) observa, a esse respeito, que no "Pantanal, a onça é a criatura que melhor realiza essa representação 'pura', 'extrema', de selvageria”. As onças encarnam, de acordo com ele, uma espécie de tipo ideal da selvageria ou da braveza, sendo que uma das consequências que tira disso é o fato de que "os indivíduos que conseguem capturá-la são distinguidos entre seus pares por sua coragem e ousadia" (Banducci, 2007: I25).

Há aqui, portanto, pelo menos aparentemente, uma convergência entre os valores regionais e aqueles do caçador naturalista representado pelo Jaguar hunting de Almeida. Nesse caso, a ambiguidade em relação aos colaboradores nativos repercute aquela que se constitui com as onças. Os primeiros são tomados ora como subalternos, incivilizados, ora como ideais de uma certa masculinidade ligada ao enfrentamento do elemento natural. E as onças, por sua vez, são caracterizadas ora como nobres inimigas, representantes de uma natureza a ser subjugada, ora como animais nocivos que devem ser eliminados. Em todo caso, à dimensão do enfrentamento com a natureza selvagem, soma-se, em ambos os casos, a dimensão "científica" de uma história natural que se propõe a preservar para a posteridade exemplares, ou espécimes, tomados como tipos ideais.

Diante de uma rede de relações locais na qual a caça é o modo de relacionamento privilegiado com as onças, podemos imaginar as dificuldades que George Shaller enfrentou quando chegou ao Pantanal para implantar seu projeto, em I977. A própria situação do campo era complicada. Por um lado, a Fazenda Acurizal, que lhe servia de base, oferecia as condições ideais para a pesquisa, com a infraestrutura de uma propriedade rural situada em pleno território do jaguar. ${ }^{22} \mathrm{Um}$ sistema de estradas e caminhos, edificações, animais de montaria, moradores locais com conhecimento do terreno, tudo isso permitiu o desenvolvimento da logística complexa implicada nas atividades de campo. Por outro lado, entretanto, a percepção das onças por parte da comunidade 
local era estruturalmente negativa. E o pesquisador aprendeu de forma traumática como as onças podiam ser vistas como fonte de prejuízo ou como ameaça, ou ainda como uma prova de coragem para os vaqueiros. De fato, a situação de conflito se tornou tão intensa que acabou impossibilitando a continuidade do projeto depois que as onças monitoradas pelos pesquisadores foram mortas pelos próprios funcionários da fazenda. A respeito desses eventos, Schaller (2007: 72) afirma:

Um dos vaqueiros relatou que as ordens para atirar em todos os jaguares tinha sido dada por Geraldo, o gerente que verificava o rancho de tempos em tempos em nome do proprietário ausente. Na opinião de Geraldo, o gado e as onças não podiam coexistir.

A relação de conflito entre onças e fazendeiros repercutia, assim, em um segundo conflito, dessa vez entre ambientalistas e moradores locais. Desiludido com os acontecimentos, ele conclui: "Duas onças-pintadas foram mortas. Se não houver uma mudança nas atitudes locais, apenas um grande parque nacional pode salvar a onça do Pantanal" (Schaller, 2007: 75).

Depois de encontrar uma nova área de pesquisa, ao sul do Pantanal, Schaller deixaria o projeto, em I980, com um sentimento explícito de frustração. Seriam dois colegas, Peter Crashaw e Howard Quigley, que dariam continuidade à pesquisa e conseguiriam por fim desenvolver um estudo consistente nos anos seguintes. Refletindo sobre os acontecimentos que levaram ao abandono da Fazenda Acurizal, Crawshaw (2006b: 19) observa:

Quando uma vez eu perguntei se [Schaller] escreveria um livro sobre seus estudos no Brasil (como havia feito em todos os outros projetos que realizou), ele respondeu que provavelmente não o faria, porque seria muito triste.

Em termos dos resultados objetivos, o projeto esclareceu aspectos importantes da ecologia das onças. Schaller já havia observado, em seu trabalho com os leões do Serengueti, que eles eram predadores oportunistas cujos hábitos alimentares estavam relacionados à disponibilidade e acessibilidades das presas. E isso podia ser medido em termos da biomassa ${ }^{23}$ disponível de cada uma delas no ambiente (Schaller, I972). O modelo elaborado a partir do leão africano serviria de base para os estudos no Pantanal, os quais incluíram pesquisas com algumas das principais presas silvestres das onças, como capivaras e jacarés, investigando como a predação afetava a dinâmica populacional desses animais.

No caso pantaneiro, o pesquisador concluiu que o gado doméstico, coexistindo com os animais selvagens, era de longe a espécie mais disponível para as onças. A quantidade de gado foi estabelecida como sendo aproximadamente dez vezes maior, em termos de sua biomassa, do que a soma de todas as espécies nativas das quais as onças se alimentavam. Confirmou-se então, com dados quantitativos e sem grandes surpresas, que o gado havia se con- 
vertido no principal item na dieta das onças-pintadas em grande parte do Pantanal (Schaller \& Crawshaw, I980). ${ }^{24}$

Em I980, a antiga fazenda Miranda Estância, ${ }^{25}$ localizada na confluência dos rios Miranda e Aquidauana, na região sul do Pantanal, proporcionou finalmente um ambiente favorável para o desenvolvimento do projeto idealizado por Schaller. A fazenda foi pioneira na adoção de medidas conservacionistas, assim como na implantação do ecoturismo nessa região, e, entre I980 e I984, Crawshaw e Quigley nela estabeleceram uma base sólida para a pesquisa. A estrutura produzida por eles envolvia o apoio dos administradores e uma relação cooperativa com vaqueiros e moradores locais, muitos deles com experiência de caça. O relatório final do projeto afirma:

Até I966, a fazenda Miranda Estância contratava caçadores profissionais para diminuir o número de felinos e a sua predação no gado. Um desses caçadores matou, em um período de 8 anos (I959-I966), 68 pintadas e 275 pardas, apenas na área da fazenda. [...] Embora essa atividade tenha sido proibida a partir de I966, o controle é difícil, e, ocasionalmente, alguns animais são mortos para "diversão" dos peões e para treinar cachorros, uma vez que um bom cachorro onceiro e um revólver 38 são os maiores símbolos de status entre os pantaneiros (Crawshaw \& Quigley, 1984).

A paisagem socioambiental do Pantanal é marcada por essa associação histórica entre criação do gado e caça. Crawshaw relata que, com o tempo, se formou na Miranda Estância uma estrutura que contava com os próprios cavalos e com cachorros para as capturas - cães que conseguiram com moradores locais, outros que eles próprios treinaram a partir daí (comunicação pessoal em outubro de 2007). Os pesquisadores conseguiram assim capturar e rastrear uma quantidade significativa de onças, usando pequenas aeronaves ultraleves para sobrevoar a área de estudo com equipamento de rádio. Com isso produziram um trabalho que se tornaria uma referência.

De fato, desde as primeiras capturas de onças no âmbito de projetos científicos no Pantanal, o método tradicional da caçada com cães mostrou-se mais eficaz do que qualquer outro, tendo sido até hoje o mais utilizado. ${ }^{26}$ No início dos anos 2000, por exemplo, três novos projetos voltados para o estudo da espécie se instalaram na mesma região em que Crawshaw e Quigley trabalharam, e todos eles contaram com a participação de caçadores nativos e cães onceiros (Azevedo \& Murray, 2007; Cavalcanti et al., 20ıо; Silveira, 2004). É significativo, nesse sentido, que um desses projetos tenha implantado um canil - o Canil Jaguaretê - no qual os pesquisadores criam e treinam cães especificamente para a captura de onças. ${ }^{27}$

O tema, porém, é controverso. Em artigo sobre os métodos de campo para o estudo das onças, Furtado et al. (2008: 4I) afirmam: "A captura de onças-pintadas com cães treinados é atualmente o método de captura mais frequente", mas observam que "é importante se considerar que a caçada de onças-pintadas é 
proibida na maior parte dos países em que a espécie ocorre e que a contratação de caçadores e cães de caça viola princípios legais e éticos" (Furtado et al., 2008: 42). Há, nesse caso, uma interface evidentemente problemática entre a caça e a conservação, que diz respeito ao fato de que as onças foram historicamente perseguidas e eliminadas por fazendeiros intermediados por caçadores e com uso de cães (e em muitos lugares continuam sendo, apesar da proibição).

Ao mesmo tempo, porém, como vimos, esses mesmos cães, assim como os conhecimentos dos caçadores nativos, foram decisivos na constituição dos estudos sobre a onça pantaneira. Esses estudos envolveram, de fato, a consolidação gradual de uma trama ${ }^{28}$ na qual onças, cães, pesquisadores, caçadores, tranquilizantes e armas de ar comprimido, transmissores de rádio, gado, vaqueiros, rastros e sinais de diversos tipos, tudo isso adquire uma configuração particular. Uma rede complexa de relações a partir da qual se produzem dados sobre o comportamento das onças e ao mesmo tempo se tecem alianças necessárias para a conservação da espécie.

Mas retomemos, ainda uma última vez, as caçadas narradas por Antonio de Almeida em Jaguar hunting. Há uma história que costura o livro todo, conferindo-lhe uma estrutura narrativa. Trata-se do embate do caçador com um determinado animal, devidamente nomeado, individualizado e condenado como matador de gado (stock killer); um fora da lei e ao mesmo tempo um adversário de valor. Neste trecho ele é apresentado ao leitor:

O jaguar que fugiu tinha uma das maiores pegadas que eu já tinha visto, medindo quinze centímetros de largura. Daquele dia em diante ele foi apelidado de Big Richard pelos vaqueiros (...) em homenagem aos pés de Richard [Mason, sócio do autor]. Muitas vezes nós tentamos encontrá-lo enquanto caçávamos com clientes nos anos seguintes, mas ele sempre fugia para o mato fechado, aleijando e matando cachorros e indo embora quando os homens se aproximavam (Almeida, I976: 50).

Big Richard é citado estrategicamente ao longo dos capítulos, à medida que o cenário para o embate com esse inimigo animal é construído, até o clímax nas páginas finais do livro. Usando recursos que remetem ao estilo de Sasha Siemel - que lhe serve de referência -, na passagem a seguir Almeida interrompe a sequência de eventos ligados à perseguição da onça para recortar um quadro estático, antecipando o desfecho da narrativa:

Uma incrível visão primitiva foi iluminada: a vinte metros de distância, com a cabeça perto do chão, Big Richard estava emitindo seu último chamado. As notas roucas ecoaram [...] por toda a floresta pantanosa que tinha, por tanto tempo, sido o seu reino (Almeida, I976: 192-I93).

O registro da morte é seguido pela medição do crânio do animal, quando o caçador se dá conta de que está diante de um prêmio maior do que esperava: 
Antes que Thornton pudesse perceber o seu erro, ele disparou o tiro. [...] Uma das balas tinha atingido o cérebro, interrompendo instantaneamente sua carreira. [...] O rei estava morto. [...] Eu pude ver que sua cabeça era fora do comum, mas não percebi na hora que tínhamos conseguido um novo recorde mundial (Almeida, 1976: 193).

Por fim, um resumo daquilo que pode ser tomado como um tipo ideal dentro do que o livro representa:

Pareceu-me perfeitamente adequado que esse velho jaguar, que tinha por tanto tempo medido forças conosco, tivesse quebrado o recorde e que agora, totalmente reconstituído pelo grande taxidermista Mario Aguilar, na Cidade do México, estivesse imortalizado para a posteridade, para um dia tomar seu lugar em um museu público (Almeida, 1976: 194).

O modelo de história natural preconizado pelo autor encontra aqui um exemplo perfeito: o adversário de valor, enfrentado em seu habitat, é imortalizado pela ciência. O abate de Big Richard é uma experiência de comunhão com a natureza e, ao mesmo tempo, um novo recorde para os registros científicos; uma caçada de tirar o fôlego e um belo exemplar para um museu de história natural.

Como contraste temos o texto de George Schaller visto na primeira parte deste artigo, que traz também a narrativa da perseguição de uma onça, capturada com a participação de Gigante. Dessa vez, porém, o objetivo é a colocação de um colar de rádio. Schaller refere-se, ainda no mesmo texto, a uma segunda onça equipada com radiocolar, que havia sido capturada com o uso de uma armadilha de caça e que estava acompanhada de uma filhote, também fêmea. Nos momentos finais do projeto, os pesquisadores constatariam que estas duas onças, mãe e filhote, haviam sido mortas a mando do capataz da fazenda. No trecho a seguir, Schaller (2007: 76-77) descreve o momento em que encontram a pele desta última:

A nosso pedido, um funcionário do serviço florestal visitou Acurizal para investigar a matança de onças. Ele também confiscou a pele de onça-pintada que Aníbal tinha escondido na casa dele. Agora, pela primeira vez eu a vejo - o jovem animal que me enganou em vida. A pele com sua triste beleza, seus olhos vazios, seu buraco de bala - eu não queria guardar esta lembrança.

O contraponto é notável em relação ao tipo ideal de animal de caça formulado por Antonio de Almeida. Big Richard, uma síntese eloquente da tradição à qual ele pertence, é o exemplar ideal preservado por taxonomia. ${ }^{29}$ A pele de onça encontrada por Schaller, por sua vez, é de uma jovem fêmea abatida pelos vaqueiros da fazenda, um animal cuja morte evidencia as dificuldades implicadas na conservação da espécie. Frágil, ameaçada pelas atividades humanas, ela não poderia oferecer um contraste maior em relação à figura do grande macho dominante. 
No trabalho que me serviu aqui como referência, Donna Haraway mostra como as representações realistas de animais no Museu Americano de História Natural estão impregnadas de um ideal de dominação moralizante, paternal e colonialista. Tanto a imagem da natureza selvagem quanto a do "homem" - em suas várias expressões indígenas e locais - estão inseridas, no caso, em uma narrativa histórica subordinada aos preceitos norte-americanos da conquista do Oeste, a fronteira selvagem. O ideal naturalista de ver tudo de lugar nenhum, de verdades científicas puras, indisputadas, é um legado dessa tradição, assim como a busca por um tipo ideal de animal. O antídoto formulado por Haraway para essa visão purificadora é uma abordagem que procura recolocar, camada após camada, os elementos de mediação que fazem parte da construção das cenas idealizadas em que os animais são expostos no museu.

Partindo dessa referência, minha intenção, na análise da literatura sobre caçada às onças, foi tornar visíveis, de um lado, os pressupostos não marcados da figura dos caçadores-narradores como homens, brancos e pertencentes a uma determinada classe social, e, de outro, a imagem da natureza como elemento a ser enfrentado, subjugado. Essa concepção da natureza, tomada como separada e sujeita ao domínio humano, é algo que fundamenta as concepções da humanidade e da animalidade que procurei abordar aqui.

A subordinação da natureza repercute, nesse caso, de diversas maneiras. Por um lado, ela remete a uma ligação entre animalidade e servidão. Os animais, nesse contexto, ora são tratados como coisas (propriedade de alguém), ora como máquinas produtivas, ora como fontes de prejuízo a ser eliminadas. Por outro lado, remete também às relações de poder que separam os homens e justificam os privilégios de uma elite que sempre reivindica para si a posição de conhecimento.

Vale lembrar que estamos falando, nesse caso, de uma sociedade rigidamente hierarquizada, em que o corte econômico entre patrões e empregados se replica em um corte racial evidente, entre fazendeiros brancos e vaqueiros indígenas e negros. Um mundo no qual um vaqueiro pode no máximo aspirar ao posto de capataz, digamos, mas provavelmente nunca será um fazendeiro. É nessa mesma chave que podemos ler o tratamento dispensado aos caçadores nativos por parte de seus empregadores brancos. Eles são empurrados para o outro lado da fronteira, são retratados como guiados por "instintos", ou então são tratados de forma paternalista (como "boys"). É essa lógica do "macho adulto branco sempre no comando", 30 a qual opera dos dois lados da fronteira humano/animal, que Haraway (I989) descreve tão bem a tradição do naturalismo ilustrado ligada a Theodore Rosevelt.

Os pressupostos dessa tradição de caçadores-naturalistas caracterizam um modo de representação da onça-pintada que vai ser colocado em xeque, em muitos de seus aspectos, no caso do Pantanal, a partir dos novos paradigmas ecológicos que se estabelecem com a entrada em cena dos projetos conserva- 
cionistas na região. Nesse sentido, as duas onças capturadas por George Schaller, enquanto ainda estavam vivas, equipadas com os dispositivos de rastreamento da biologia da conservação, abriram caminho para a escrita de um novo tipo de história natural, assim como um novo paradigma na produção de conhecimento científico.

A ideia de que esse novo paradigma substituiu o anterior, entretanto, é limitada. Primeiro, porque a caça, seja ela definida em termos culturais seja em termos utilitários, é uma realidade que persiste e com a qual a conservação da onça pantaneira, na prática, precisa necessariamente lidar. E, por fim, no sentido de que, na aproximação entre caça e conservação, o tema do conflito parece não oferecer uma definição final das relações em curso. Trata-se antes de um contexto de efetuação entre outros, incluindo alianças e linhas de continuidade como aquelas que podemos observar na história do cachorro Gigante.

Recebido 6/I/20I9 | Revisto 4/4/20I9 | Aprovado 8/5/2019

Felipe Süssekind é professor do Departamento de Ciências Sociais da PUC-Rio. Doutor em Antropologia Social pelo Museu NacionalUFRJ e mestre em história pela PUC-Rio. Autor de O rastro da onça: relações entre humanos e animais no Pantanal (20I4). Áreas de interesse: estudos multiespécies; antropologia das ciências; estudos socioambientais. 


\section{NOTAS}

I Agradeço ao professor Eduardo Viveiros de Castro, orientador no Doutorado. Ao CNPQ, que financiou a pesquisa. A Peter Crawshaw pela entrevista concedida.

2 Pantanal é o bioma formado pelas planícies alagáveis da região central da América do Sul, ao longo da bacia do rio Paraguai. É uma região conhecida pela biodiversidade que abriga, incluindo uma das maiores densidades de onçaspintadas do continente. O local de pesquisa de Schaller era próximo ao atual Parque Nacional do Pantanal Matogrossense.

3 Para um histórico da telemetria no Brasil, ver Crawshaw (2006a).

4 George Schaller trabalhou, numa perspectiva conservacionista, com algumas das espécies mais icônicas dos grandes mamíferos no mundo. Ele foi um dos primeiros zoólogos a estudar os gorilas-das-montanhas, na África Central (Schaller I964) e, depois do Pantanal, iria trabalhar com o panda-gigante, na China (Schaller I985).

5 Nessa e nas demais citações de originais em idioma estrangeiro as traduções são minhas.

6 Lei de Proteção à Fauna (lei no 5.197, 1967).

7 Lei de Crimes Ambientais (lei nº 9.605, de I998).

8 A legislação vigente afirma: "§ $2^{\circ}$ - "Será permitida, mediante licença da autoridade competente, [...] a destruição de animais silvestres considerados nocivos à agricultura ou à saúde pública" (lei no 5.197, I967). Disponível em: <http://www.rbma.org.br/anuario/pdf/legislacao_I3.pdf $\geq$. Acesso em mar. 2018.

9 O administrador de uma das fazendas que visitei em minha pesquisa de campo no Pantanal me disse: "antigamente tinha muita onça [...] naquele tempo, um bom cachorro onceiro valia vinte cabeças de gado, quando era cachorro bom mesmo, mestre" (Süssekind, 20I4).

Io A submissão ao julgo humano, no caso dos cães de caça, aponta para um processo mais de doma do que de domesticação. Eles precisam preservar seus instintos de caça, mas, ao mesmo tempo, têm seu lado selvagem controlado pela ação dos caçadores. Um cão mestre que não corres- 
ponder a expectativa do seu dono e perseguir outro animal que não a onça, por exemplo, será duramente castigado, com uma violência que encontra paralelos na "doma bruta" usada com os animais de montaria no Pantanal. Ver, a esse respeito, Süssekind (2017; 20I4) O couro das onças era muito valorizado no Pantanal até a caça comercial ser proibida. Sua gordura costumava ser aproveitada na medicina popular, e mesmo a carne era comida com certa frequência (Roosevelt, I976; Almeida, I976).

I2 Ver a esse respeito: <https://huntforever.org/20I5/06/22/

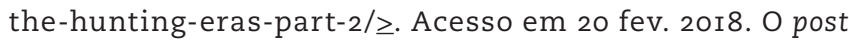
em questão, de autoria de Bert Klineburger, reporta que Almeida e Mason se conheceram durante uma caçada guiada por este último em Angola, e que a partir de então começaram a organizar expedições no Brasil. Foi publicado em um blog chamado Hunt Forever, ligado ao Safari Club International, organização sediada em Tucson, no Arizona que advoga pela prática e divulgação da caça esportiva..

I3 Roosevelt cumpriu dois mandatos como presidente dos EUA até perder as eleições de I9I2.

I4 O rio da Dúvida foi posteriormente renomeado rio Roosevelt. Ver, a esse respeito, o ótimo livro de Candice Millard (2007).

I5 A tradução em português seria algo como "Patriarcado do urso de pelúcia”. Na tradução se perde a ligação que esses brinquedos têm, nos EUA, com a figura do ex-presidente. Eles se popularizam com esse nome a partir de uma série de caricaturas publicadas na imprensa norte-americana, no início do século $X X$, representando uma situação de caça em que Roosevelt teria poupado um filhote de urso. Disponível em: <https://en.wikipedia.org/wiki/Teddy_bear>. Acesso em 26 dez. 2018.

I6 Os dados sobre animais abatidos na expedição de Roosevelt à África são estonteantes: "Ao todo, Roosevelt e companheiros mataram e caçaram mais de II.397 animais, desde insetos e toupeiras a hipopótamos e elefantes. [...] Toneladas de animais e suas peles em sal foram enviados para Washington". Disponível em: <https://pt.wikipedia. 
org/wiki/Theodore_Roosevelt\#cite_note-SIA-52>. Acesso em 20 fev. 2018

I7 Escrevendo em inglês, Siemel usa, estranhamente, o termo "tigre", em espanhol, em vez de "jaguar" ou "onça", que são os termos usados em português. Almeida (I976, p. 6I) comenta a esse respeito o seguinte: "O nome usado para o jaguar em todo Brasil é 'onça' [...] A palavra 'tigre' nunca é usada no Brasil. Por que, em todos os seus livros, Sasha Siemel sempre se refere ao jaguar como 'tigre', considerando que ele nunca caçou fora do Brasil, é uma questão que sempre me intrigou". De acordo com minha hipótese, isso se deve à vinculação da obra de Siemel aos livros de aventura referentes à conquista do Oeste nos EUA.

I8 Uma coleção de fotografias do acervo de Sasha Siemel encontra-se exposta na pousada da Fazenda San Francisco, em Miranda (MS), na qual fiz parte de meu trabalho de campo (Süssekind, 20I4). O caçador com a mulher e o filho, sorridentes, aparecem nelas portando zagaias, espingardas ou arco e flecha, quase sempre agachados atrás do corpo de um animal selvagem, na maioria dos casos onças-pintadas. A coleção inclui também instantâneos de uma filmagem em que o caçador enfrenta uma onça usando uma zagaia. Essas filmagens foram realizadas em um cercado construído na fazenda Miranda Estância, onde Siemel viveu, e ajudaram na divulgação de seus livros, publicados nos EUA (Benevides \& Leonzo, I999)

I9 Akeley criou os famosos dioramas do Natural History Museum, com animais empalhados expostos com simulação de movimento em cenários realistas.

20 Haraway refere-se aos dez anos de desenvolvimento de câmeras que Akeley teve que esperar para filmar com sucesso a caçada do leão com a lança, imagem que seria fundamental na constituição de um ideal do homem primitivo que ficou conhecido como Man, the Hunter (Haraway, I989: 28).

2 I O caráter ambíguo desses personagens tende a ser redefinido, de alguma forma, no campo da biologia da conservação, quando caçadores são incorporados aos projetos de campo científicos como mateiros, guias ou "práticos" de campo. Abordei esse tema de forma mais sistemática em trabalhos anteriores (Süssekind, 20I4, 20I7). 
22 Havia na época um acordo firmado entre o proprietário da fazenda e o órgão ambiental do governo brasileiro (IBDF), pelo qual a área seria comprada por este último e transformada em reserva ambiental. Peter Crawshaw reporta que a negociação não deu certo na época, sendo que apenas 20 anos depois o processo se concretizou: "em I995, essa fazenda foi comprada pela Nature Concervancy (NC), sob responsabilidade da Fundação Ecotrópica, em Cuiabá, MT, como uma reserva privada; ela é hoje uma extensão virtual do Parque Nacional adjacente" (Crawshaw 2006b).

23 Biomassa é a medida usada na biologia para estimar a soma da massa do conjunto dos indivíduos de uma espécie.

24 Em linhas gerais, o que as pesquisas apontaram é que não é a falta de presas naturais que faz as onças atacarem o gado, mas antes a disponibilidade de um novo recurso alimentar mais fácil e acessível do que as espécies de presas nativas (Crawshaw \& Quigley 1984, Azevedo \& Murray 2007, Cavalcanti et al., 2010). Mais de 95\% da área do Pantanal é ocupada por propriedades privadas, habitadas atualmente por uma quantidade aproximada de quatro milhões de cabeças de gado, de acordo com dados do Instituto Brasileiro de Geografia e Estatística (IBGE).

25 A Miranda Estância tem sua origem ligada a um grande empreendimento inglês de exportação de carne bovina e foi nacionalizada de forma forçada em I952, sendo comprada por empresários brasileiros (Benevides \& Leonzo I999: I49).

26 O uso de armadilhas com laços, considerado mais seguro e eficaz, tem sido empregado em capturas de onças para estudos recentes realizados no Brasil, substituindo em muitos casos o uso de cães farejadores.

27 O Projeto Onça-Pintada no Pantanal, sediado na Fazenda Caiman (MS), é desenvolvido pelo Instituto Onça-Pintada, uma ONG conservacionista que atua em diversas partes do Brasil. Informações a respeito do canil estão disponíveis em: <http://www.jaguar.org.br/pt/sobre-nos/canil-jaguaret/>. Acesso em 5/I/20I9.

28 Recorro ao termo "trama", neste caso, pensando no modo como Donna Haraway (2016) se apropria da imagem da 
brincadeira da cama de gato (string figures ou simplesmente SF). SF é a figura conceitual a partir da qual propõe uma releitura tanto para a ideia da "rede", desenvolvida no âmbito da teoria-ator-rede (Latour, 20I2; Law, 2009), quanto para a ideia da "malha" (meshwork), proposta criticamente por Ingold (20I5).

29 Sobre a relação de Carl Aekeley com os espécimes coletados por ele, expostos nos dioramas do Museu Americano de História Natural, Donna Haraway (I989: 34) afirma: "O conhecimento científico anulou a morte; só a morte antes do conhecimento era final, um ato abortivo na história natural do progresso".

30 "O macho adulto branco sempre no comando, e o resto ao resto", diz Caetano Veloso na canção "O Estrangeiro". In: O Estrangeiro. Phillips, I989.

\section{REFERÊNCIAS BIBLIOGRÁFICAS}

Almeida, A. de. (I976). Jaguar hunting in Mato Grosso. [s.1.]: Stanwill Press.

Azevedo Fernando Cesar Cascelli Murray, Dennis L. (2007). Evaluation of potencial factors predisposing livestock to predation by jaguars. The Journal of Wild Life Management, 7I/7, p. 2379-2386.

Banducci Jr., Álvaro. (2007). A natureza do pantaneiro. Campo Grande, MS: Ed. UFMS.

Benevides, Cezar \& Leonzo, Nanci. (I999). Miranda Estância. Ingleses, peões e caçadores no Pantanal mato-grossense. Rio de Janeiro: FGV Editora.

Cavalcanti, Sandra M. C. et al. (20I0). Jaguars, Livestock, and People in Brazil: Realities and Perceptions Behind the Conflict. Staff Publications. Paper 9I8. Lincoln: USDA National Wildlife Research Center.

Crawshaw, Peter G. (2006a). Histórico da radiotelemetria no estudo de felinos no Brasil. I Simpósio de Radiotelemetria do Brasil. Floresta Nacional de São Francisco de Paula, 
RS. Ibama. Disponível em: <https://slidex.tips/download/ historico-da-radio-telemetria-no-estudo-de-felinos-nobrasil>. Acesso em 7 maio 2018.

Crawshaw, Peter G. (2006b). The history of carnivore research in Brazil. In: Morato, Ronaldo Gonçalves et al. (orgs.). Manejo e conservação de carnívoros neotropicais. São Paulo: Edições Ibama, p. I5-38.

Crawshaw, Peter G. \& Quigley, Howard B. (I984). A ecologia do jaguar ou onça-pintada (panthera onca palustris) no Pantanal mato-grossense. In: Estudos bioecológicos do Pantanal mato-grossense - relatório final - parte I. Brasília: Instituto Brasileiro de Desenvolvimento Florestal.

Furtado, Mariana M. et al. (2008). Studying jaguars in the wild: past experiences and future perspectives. Cat News, special issue 4, The Jaguar In Brasil. Bern: Jaguar Conservation Fund, p. 4I-47.

Haraway, Donna. (2016). Staying with the trouble: Making Kin in the Chthulhucene. Durham/London: Duke University Press.

Haraway, Donna. (1989). Teddy bear patriarchy taxidermy in the garden of eden, New York City, I908-I936. In: Primate visions: gender, race, and nature in the world of modern science. London: Routledge, p. 26-58.

Ingold, Tim (2015). Estar vivo: ensaios sobre movimento, conhecimento e descrição. Petrópolis: Vozes.

Law, J. (2009). Actor network theory and material semiotic's. In: Turner, Bryan S. (ed.). The new Blackwell companion to social theory. 3rd ed. Oxford: Blackwell, p. I4II58.

Latour, Bruno. (2012) [2005]. Reagregando o social: uma introdução à Teoria Ator-Rede. Salvador/Bauru: Edufba/Edusc. Millard, Candice. (2007). O Rio da Dúvida - A sombria viagem de Theodore Roosevelt e Rondon pela Amazônia. São Paulo: Companhia das Letras

Morato, Ronaldo G. et al. (orgs.). (2006). Manejo e conservação de carnívoros neotropicais. São Paulo: Edições Ibama. Roosevelt, Theodore. (I976) [I9I4]. Nas selvas do Brasil. Rio de Janeiro: Itatiaia. 
Schaller, George B. (2007). A naturalist and other beasts: tales from a life in the field. San Francisco: Sierra Club Books.

Schaller, George. (1985). The giant pandas of Wolong. (Com $\mathrm{Hu}$ Jinchu, Pan Wenshi \& Zhu Jing). Chicago/London: The University of Chicago Press.

Schaller, George. (1972). The Serengeti lion. A study of predator-prey relations. Chicago/London: The University of Chicago Press.

Schaller, George. (I964). The year of the gorilla. Chicago: The University of Chicago Press.

Schaller, G.B. \& Crawshaw, P.G. (I980). Movement patterns of jaguar. Biotropica, I2, p. I6I-I68.

Schaller, G.B. \& Vascooncelos, J.M.C. (I978). Jaguar predation on capybara. Z. Säugetierkunde, 43, p. 296-30I.

Siemel, Sasha. (1953). Tigrero! New York: Ace Books.

Silveira, Leandro. (2004). Ecologia comparada e conservação da onça-pintada (panthera onca) e onça-parda (puma concolor), no cerrado e pantanal. Tese de Doutorado. PPGBA/ Universidade de Brasília.

Silveira, Leandro et al. (2008). Management of domestic livestock predation by jaguars in Brazil. Cat News, special issue 4, The Jaguar In Brasil. Bern: Jaguar Conservation Fund, p. 26-30.

Süssekind, Felipe. (20I7). Onças e humanos em regimes de ecologia compartilhada. Horizontes Antropológicos, Porto Alegre, $23 / 48$, p. 49-73.

Süssekind, Felipe. (20I4). O rastro da onça: relações entre humanos e animais no Pantanal. Rio de Janeiro: 7 Letras. 


\section{Palavras-chave \\ Caça; conservação; onça-pintada; \\ Pantanal; conflito.}

\section{A HISTÓRIA DE GIGANTE: CONSERVAÇÃO E CAÇA NO PANTANAL}

\section{Resumo}

Este artigo aborda o primeiro estudo de campo científico sobre a ecologia da onça-pintada, realizado no final dos anos I970, no Pantanal brasileiro. O ponto de partida é um texto escrito por George Schaller, responsável por aquele estudo, no qual podemos acompanhar a história do cão chamado Gigante. Trata-se de um personagem que atravessa fronteiras difíceis entre práticas de conservação e práticas de caça ou entre um texto conservacionista e um livro escrito por um caçador profissional e guia de safáris. Ao transitar pelas fronteiras entre essas narrativas, a trajetória de Gigante revela diferentes imagens da natureza selvagem, as quais se traduzem nas figuras de onças ameaçadoras ou ameaçadas.

\section{GIANT STORY: CONSERVATION AND HUNTING IN THE BRAZILIAN PANTANAL}

Keywords

Hunting; conservation; jaguar;

Pantanal; conflict.

\section{Abstract}

This article retraces the first scientific field study on the ecology of jaguars, conducted in the late I970s in the Brazilian Pantanal. The starting point is a text written by George Schaller, responsible for the research in question, in which we can follow the story of a dog called Gigante (Giant). The protagonist traverses the problematic boundaries between the practices of conservation and hunting, or between a conservationist text and a book written by a safari guide and professional hunter. In crossing the boundaries between these narrative genres, Gigante's trajectory reveals different images of wild nature, which translate into the figures of threatening or threatened jaguars. 